\title{
Echinococcus Alveolaris: Presenting as a Cerebral Metastasis
}

\section{Serebral Metastaz Şeklinde Ortaya Çıkan Ekinokokus Alveolaris}

\author{
Nuriye Guzin OZDEMIR ${ }^{1}$, Ali KURT ${ }^{2}$, Dogan Nasır BINICI ${ }^{3}$, Kerem Mazhar OZSOY ${ }^{1}$ \\ ${ }^{1}$ Erzurum Regional Education and Research Hospital, Department of Neurosurgery, Erzurum, Turkey \\ ${ }^{2}$ Erzurum Regional Education and Research Hospital, Department of Pathology, Erzurum, Turkey \\ ${ }^{3}$ Erzurum Regional Education and Research Hospital, Department of Internal Medicine, Erzurum, Turkey
}

Correspondence address: Nuriye Guzin OZDEMIR / E-mail: guzozdemir@yahoo.com

\begin{abstract}
Echinococcus multilocularis (EM) is caused by the larval stage of the tapeworm. The main endemic regions for human alveolar echinococcosis are Central Europe, Russia, Turkey, Japan, China, Eastern France, North America. EM is an endemic disease in Turkey and especially common in the eastern Anatolia Region as seen in our case. The liver is the primary focus of the disease, cerebral localization is rare. Cerebral hydatid disease is approximately $5 \%$ of alveolar hydatid cases and generally considered to be fatal. Surgical treatment should be considerd whenever possible. We present a case of cerebral alveolar hydatid disease that was thought to be cerebral metastasis.
\end{abstract}

KEYWORDS: Echinococcus alveolaris, Cerebral metastasis, MRI, Surgical treatment

öz

Echinococcus multilocularis'in (EM) etkeni parazitin larval evresidir. İnsanlarda görülen alveolar ekinokokosisde ana endemik bölgeler Orta Avrupa, Rusya, Türkiye, Japonya, Çin, Doğu Avrupa ve Kuzey Amerika'dır. EM Türkiye'de endemik bir hastalıktır ve bizim vakamızda görüldüğü gibi özellikle Doğu Anadolu bölgesinde sıktır. Hastalığın primer odağı karaciğer olup serebral yerleşim nadirdir. Serebral hidatik hastalığı alveolar hidatik vakalarının yaklaşık \%5'idir. Bu vakada serebral metastaz ön tanısıyla değerlendirilen serebral alveolar hidatik hastalığını sunduk.

ANAHTAR SÖZCÜKLER: Ekinokokus alveolaris, Serebral metastaz, MRG, Cerrahi tedavi

\section{INTRODUCTION}

Echinococcus multilocularis (E. multilocularis) is caused by the larval stage of the tapeworm. The liver is the primary focus of the disease and cerebral localization is rare. Cerebral occurrence of $\mathrm{E}$. multilocularis is approximately $1 \%$, and considered to be fatal $(1,3,4)$. Cerebral parasitoses are seen as specific lesions radiologically. We present a case of cerebral alveolar hydatid disease although it was thought to be cerebral metastasis or brain abscess in preoperative radiological investigations.

\section{CASE REPORT}

A 44-year-old man was admitted to our hospital with complaint of severe headache and weakness. He had been working in a furnace room under bad working conditions for a long time. Four months ago, he began to vomit and had severe progressive headache that did not respond to medication. On neurological examination he was conscious, dysphasic, pupillas were isocoric and no motor and sensory deficit was detected. No abnormal sign was shown after laboratory examination. Computed tomography (CT) showed multiple intracranial lesions, located in right frontal and left temporal region, sized $38 \times 36 \mathrm{~mm}$ both, which were thought to be metastases. Magnetic resonance imaging (MRI) showed anterior and temporal lesions with ring enhancement and severe cerebral edema of the frontal lesion. A small cerebellar lesion was also observed on the left side (Figures 1, 2). A positron emission tomography (PET) scan was also performed to rule out the lesion, and the lesion was thought to be an abscess instead of metastasis. Thorax and abdominal $\mathrm{CT}$ and abdominal ultrasonography were performed to find a primary focus related with metastasis; but the results were negative and no primary origin was also found in the liver. No abnormal physical examination was found except his limited cooperation.

An antiedemal and antiepileptic therapy was commenced. The patient's relatives refused the operation. Two days later he was admitted to the hospital with the patient in precoma stage. He was unconscious, pupillary reflexes were absent, pupils were dilated and the motor response was extensor.

The patient was taken to emergency surgery. A frontal craniotomy was done to expose the lesion. There was severe edema although intensive antiedemal therapy was given. The lesion was extraparenchymal giving a meningiomalike appearance. It was located in the right anterior cranial fossa. The size was $38 \times 36 \mathrm{~mm}$ and the lesion was adherent 
to the anterior region. Since it would be harmful to extirpate it totally, the upper side was resected first. It contained a semisolid, necrotic, pus-like fluid. It could be considered to be an abscess, but the capsule was too thick. Then the bottom side was carefully dissected and the lesion was totally resected. The hemostasis was done in the cavity and the dura was water-tight closed.

After the operation the patient did not need an intensive care unit follow-up and was taken to the clinic. Antiedemal therapy was given again for one week. The pathological diagnosis revealed Echinococcosis multilocularis after the first operation. A left temporal craniotomy was then performed with a second operation and the lesion was totally extirpated with the same procedure. The patient recovered well after

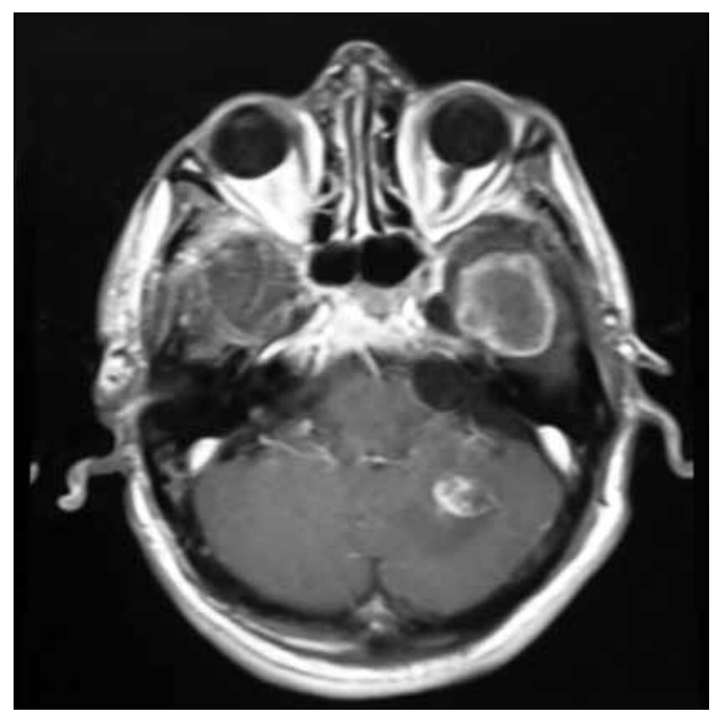

Figure 1: T-1 weighted contrast enhanced axial image shows left anterior temporal pole located ring enhancing cystic lesion.

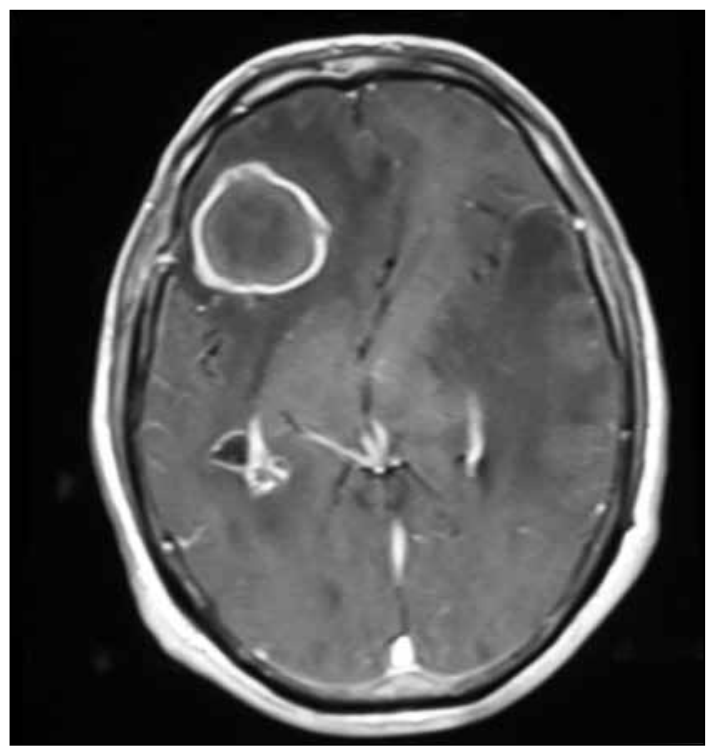

Figure 2: T-1 weighted contrast enhanced image shows right frontal ring enhancing lesion and left temporoparietal edema. the second operation. The second pathologic diagnosis also revealed Echinococcosis multilocularis (Figures 3-5). After the first pathological examination, the patient was started $800 \mathrm{mg} /$ day albendazole treatment.

As the lesion size was small and did not lead to fourth ventricular obstruction, no surgery was performed on the cerebellar lesion and it was left to be treated with albendazole.

Control MRI was obtained and it was seen that the cerebellar lesion was not enlarged and no new lesions were observed in the operation regions (Figures 6,7 ). The patient has been observed for 24 months. No neurological deficit was observed on follow-up.

\section{DISCUSSION}

Alveolar hydatid disease is a morphologically and biologically distinct entity caused by E. multilocularis. Echinoccus multilocularis and E. granulosus are both endemic in Turkey (4). Humans serve as intermediate hosts. The disease is acquired by oral ingestion of the eggs of the parasite.

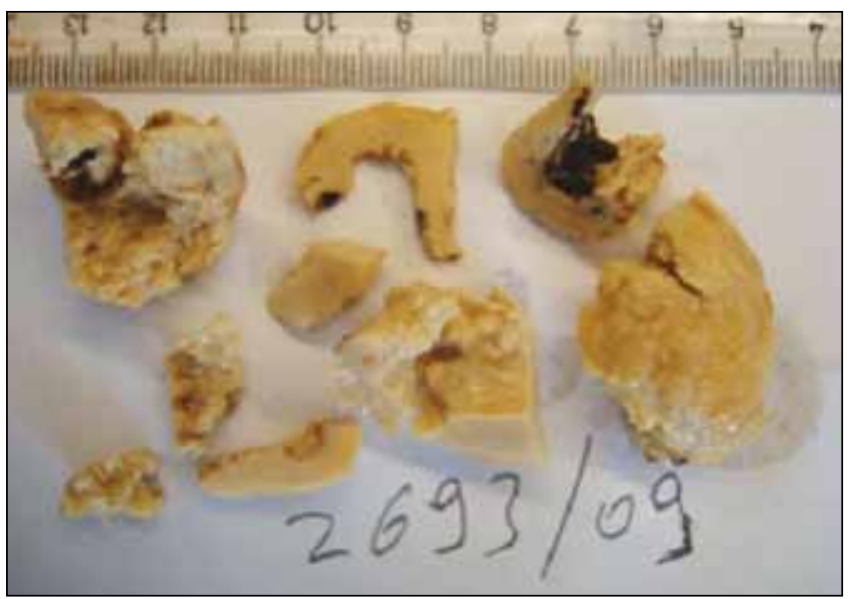

Figure 3: Macroscopic view of the excised lesion shows $2-3 \mathrm{~cm}$ yellow-white, cystic macroscopic structures.

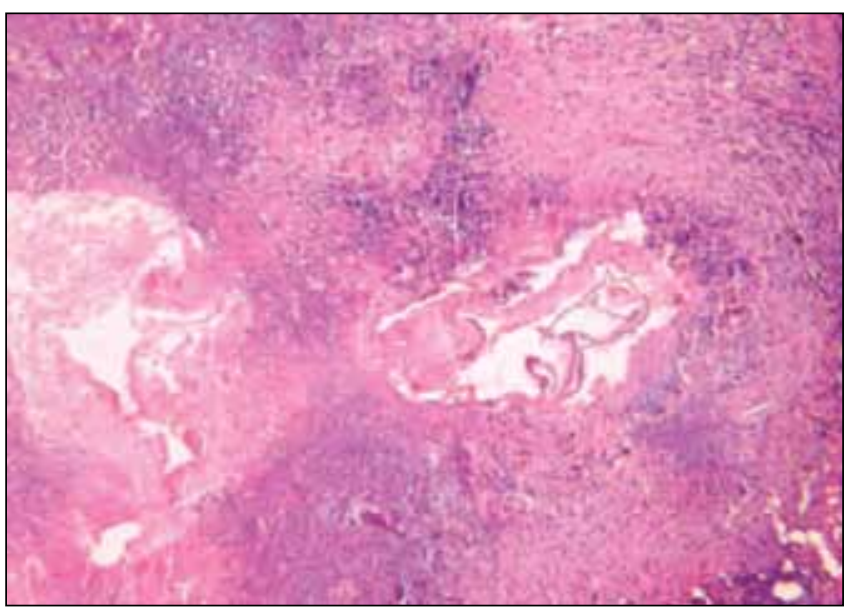

Figure 4: $H \& E$ x40 light microscopic vision shows cystic lesions surrounded by cuticular membrane and perilesional inflammatory reaction is seen. 


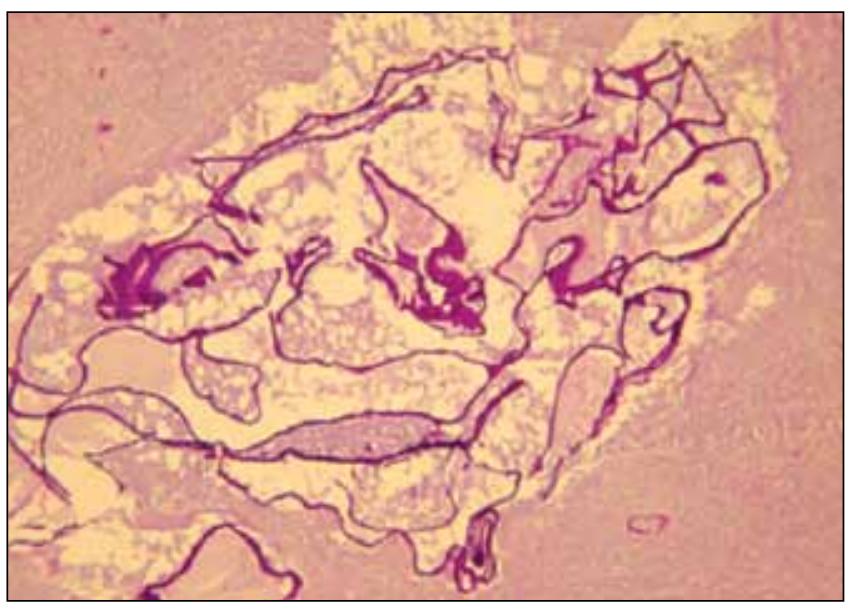

Figure 5: PAS x40 light microscopic vision shows cyst walls of $\mathrm{E}$. alveolaris.

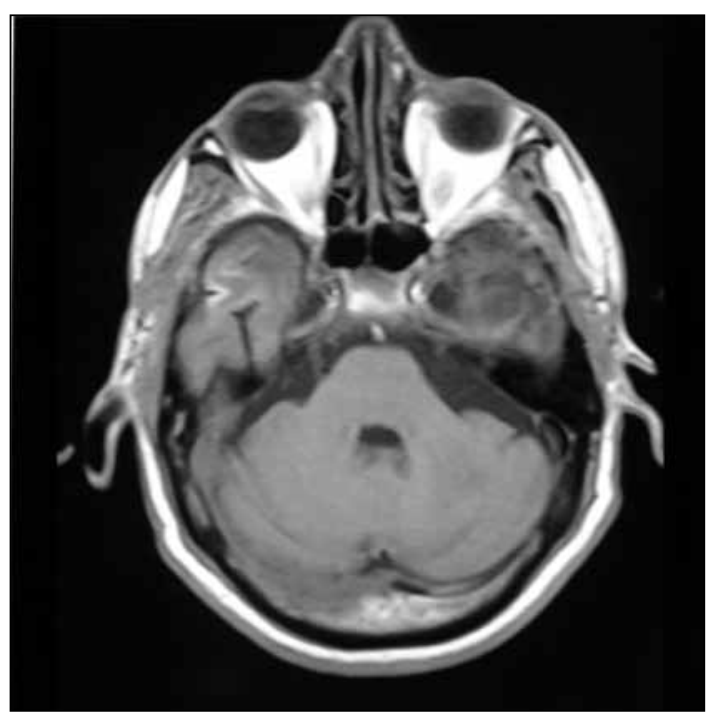

Figure 6: Control MRI showing cerebellar lesion was not enlarged.

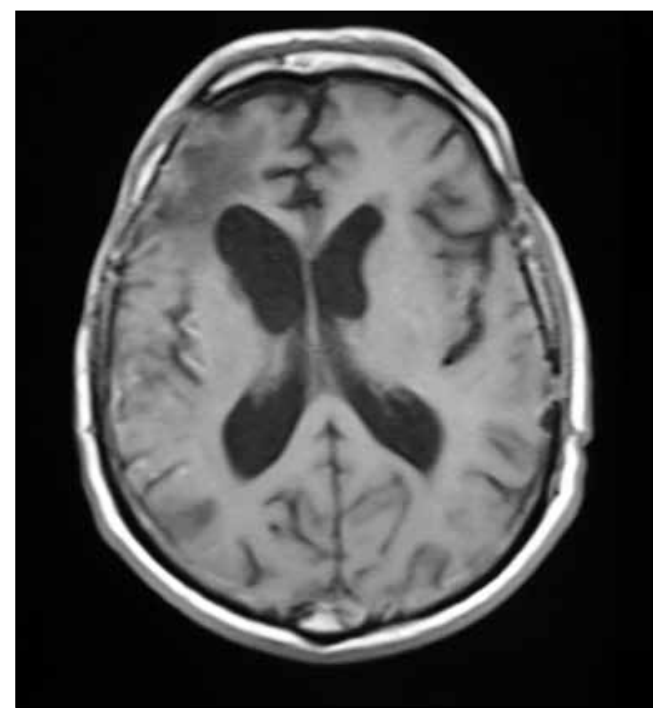

Figure 7: Control MRI showing no new lesions.
Lesions generally develop in the liver and may spread to the thyroid, bone, vertebra, scrotum, spleen, ovary, heart, kidney, peritoneum, lymph nodes, rectus muscle, knee, lacrimal sac, palpebra and occasionally the nervous system $(1,7,8,16)$.

The initial lesion of multilocular cyst hydatid is hydatid and the surrounding membranes, the germinative membrane, and an external stratified protective membrane. The germinative membrane produces scolies and the secondary cysts by external vesiculation. The fertile cysts communicate with each other and give the lesion its alveolar appearance. Necrosis may result due to cytotoxic effect of the vesicular fluid.

Treatment involves chemotherapy with benzimidazole derivatives (albendazole, mebendazole) and surgery for accessible lesions. Cure is achieved only if the lesion is completely resected. Treatment may prolong the patient's survival time $(4,8,9,13)$.

Intracerebral location is rarely seen in only $1 \%$. The clinical features are not specific. Neurological disturbances such as dysartria, aphasia (as seen in our patient), hemiparesis, increased intracranial pressure, epilepsy, skull deformity and cranial nerve palsies have been reported (4). Cerebral echinococcus alveolaris is usually related to immune suppression $(3,10,11,14,18)$. Our patient has worked in a furnace room as a furnaceman under bad conditions for a long time.

The early stage of experimentally-induced secondary cerebral alveolar echinococcosis was investigated by the use of MRI and immunoblot (western blot) analyses in one study (2). The T2-weighted images revealed a hyperintense region in the cerebral cortex two weeks after injection of the homogenate. At 3 weeks after injection, this region was found to have cysts on the basis of the results of the histologic examination. T2weighted and proton density MRI images showed signal void regions corresponding to hyperplasia and subsequent calcification of the cuticle layer at six and 13 weeks after injection. At nine weeks after injection echinococcosis alveolaris was discernible by use of western blot analysis. As a result, MRI was found to be more suitable method in the early detection of secondary cerebral echinococcosis alveolaris $(2,5,6)$. Nuclear magnetic resonance analysis revealed that brain metabolites altered in jirds infected with alveolar echinococcus in one study. Concentrations of glutamate, aspartate, glycine, taurine, glutamine, alanine glycerophosphocholine and phosphocoline were decreased whereas phosphocreatine and $\mathrm{N}$-acetylaspartate were increased (12). In our case we did not perform blot analysis and used CT and MRI and PET scan as diagnostic tools.

CT and MRI features are characteristic and show a grape-like, multilocular cystic mass with definite margins. Calcification and peripheral edema is commonly seen. Lesions appear as solid, semisolid, or multilocular. Single or multiple lesions are observed. Contrast enhancement is seen within the region of inflammatory reaction around the cysts $(15,17)$. In our case, 
CT and MRI showed well-defined cystic lesion with peripheral ring enhancement.

Cerebral Echinococcus alveolaris rarely seen in the Eastern Anatolia Region is the highest region, especially originating from Erzurum as seen in our case (4). Surgery is the radical solution for the accessible lesions; but the patients are generally admitted at a later stage. Our patient was admitted to hospital in a suitable time and after resection of those two lesions with following chemotherapy with albendazole he is doing well during the 5-month follow-up period. Surgical treatment should be considered with chemotherapy instead of only medication in appropriate patients.

\section{REFERENCES}

1. Algros MP, Majo F, Bresson-Hadni S, Koch S, Godard J, Cattin F, Delbosc B, Kantelip B: Intracerebral alveolar echinococcosis. Infection 1:63-65, 2003

2. Asanuma $T$, Matsumoto $Y$, Takiguchi $M$, Inananami $O$, Nakao M, Nakaya K, Ito A, Hashimoto A, Kuwabara M: Magnetic resonance imaging and immunoblot analyses in rats with experimentally induced cerebral alveolar echinococcosis. Comp Med 53:649-656, 2003

3. Aydin Y, Barlas O, Yolas C, Aydin IH, Ceviz A, Aladag A, Oren D, Akdemir D: Alveolar hydatid disease of the brain. Report of four cases. J Neurosurg 65:115-119, 1986

4. Aydinli B, Aydın U, Yazici P, Ozturk G, Onbas O, Polat KY: Alveolar Echinococcosis of liver presenting with neurological symptoms due to brain metastases with simultaneous lung metastasis: A Case Report. T Parazitol Derg (Acta Parasitologica Turcica) 32:371-374, 2008

5. Bresson-Hadni S, Vuitton DA, Bartholomot B, Heyd B, Godart D, Meyer JP, Hrusovsky S, Becker MC, Mantion G, Lenys D, Miguet JP: A twenty-year history of alveolar echinococcosis; analysis of a series of 117 patients from eastern France. Eur J Gastroenterol Hepatol 12:327-336, 2000

6. Bukte Y, Kemaloglu S, Nazaroglu H, Ozkan U, Ceviz A, Simsek M: Cerebral hydatid disease: CT and MR imging findings. Swiss Med Wkly 134:459-467, 2004
7. Hakan T, Aker F: A case report of fatal echinococcosis. Annals of Neurosurgery 1:14-19, 2001

8. Isik N, Silav G, Cerci A, Karabagli P, Elmaci I, Kalelioglu M: Cerebral alveolar echinococcosis. A case report with MRI and review of the literature. J Neurosurg Sci 51:145-151, 2007

9. Kondo H, Wada Y, Bando G, Kosuge M, Yagi K, Oku Y: Alveolar hydatidosis in a gorilla and a ring-tailed lemur in Japan. J Vet Med Sci 58:447-449, 1996

10. Lianes EG, Stibal A, Mühlethaler K, Vajtai I, Hausler R, Caversaccio $\mathrm{M}$ : Echinococcosis presenting as an otogenic brain abscess: An unusual lesion of the middle ear cleft and temporal lobe. Auris Nasus Larynx 35:115-120, 2008

11. Ma L, Liu WK, Mao BY, Zhang YK: An Pchinococcosis multilocularis presenting as a giant anterior cranial basilar tumor. Neurol Sci 30:247-249, 2009

12. Modha A, Novak M, Blackburn BJ: Alteration in brain metabolites of jirds infected with alveolar Echinococcus. J Parasitol 83:764-766, 1997

13. Oktar N, Karabiyikoglu M, Demirtas E, Altintas N, Korkmaz M, Ozdamar N: Cerebral alveolar echinococcosis. Review of the literature and report of a case. Norol Bil D 16:1-10, 1999

14. Paul M, Stefaniak J, Rychlicki W, Komarnicki M, MazurRoszak M: Role of adhesion molecules in a determination of progression stages and clinical prognosis of patients with Echinococcus multilocularis. Wiad Parazytol 50:483-489, 2004

15. Senturk S, Oguz KK, Soylemezoglu F, Inci S: Cerebral alveolar echinococcosis mimicking primary brain tumor. AJNR Am J Neuroradiol 27:420-422, 2006

16. Taratuto AL, Venturiello SM: Echinococcosis. Brain Pathol 7:673-679, 1997

17. Tuzun M, Altınors N, Arda IS, Hekimoglu B: Cerebral hydatid disease CT and MR findings. Clin Imaging 26:353-357, 2002

18. Yang YR, Vuitton DA, Jones MK, Craig PS, McManus DP: Brain metastasis of alveolar echinococcosis in a hyperendemic focus of Echinococcus multilocularis infection. Trans R Soc Trop Med Hyg 99:937-941, 2005 